\title{
Gastric Pneumatosis: Emphysematous Gastritis versus Gastric Emphysema
}

\author{
Amit Kumar Paliwal ${ }^{1}$ Sachin Girdhar ${ }^{2}$ Somali Pattanayak ${ }^{1} \quad$ Brajesh Kumar $^{3}$
}

${ }^{1}$ Department of Radiodiagnosis, Military Hospital Dehradun, Dehradun, Uttarakhand, India

${ }^{2}$ Department of Radiodiagnosis, Military Hospital Gaya, Gaya, Bihar, India

${ }^{3}$ Department of Surgery, Military Hospital Dehradun, Dehradun, Uttarakhand, India

J Gastrointestinal Abdominal Radiol ISGAR 2019;2:151-154

\begin{abstract}
Address for correspondence Amit Kumar Paliwal, MD, Department of Radiodiagnosis and Imaging, Military Hospital Dehradun, Garhi Cantt, Dehradun 248001, Uttarakhand, India (e-mail: amit_paliwal82@yahoo.co.in).
\end{abstract}

\begin{abstract}
Keywords

- emphysematous

gastritis

- gastric emphysema

- gastric pneumatosis

Presence of air in the wall of the stomach is known as gastric pneumatosis. It may be associated with a benign condition like gastric emphysema (GE) to life threatening condition emphysematous gastritis (EG). Differentiation between two entities based on clinical presentation, predisposing factors, and radiological findings is important as EG has more complications and higher rates of mortality. The treatment in GE is conservative while treatment in EG is evolving. We present a case of a diabetic patient who developed EG following abdominal surgery and managed conservatively with favorable outcome.
\end{abstract}

\section{Introduction}

Air in the wall of the stomach is called gastric pneumatosis, which is a rare finding and may be associated with a benign condition like gastric emphysema (GE) to life threatening condition emphysematous gastritis (EG). ${ }^{1}$ We present a case of a diabetic patient who developed EG following abdominal surgery and managed conservatively with favorable outcome.

\section{Case Report}

A 64-year-old known diabetic female underwent rectopexy for rectal prolapse. On third post-op day, she developed severe pain in the epigastric region with vomiting. Clinically, she had fever (temperature: $100.8^{\circ} \mathrm{F}$ ), tachycardia (pulse: 108/min), and hypotension (blood pressure: $86 / 60 \mathrm{~mm} \mathrm{Hg}$ ). She also had tenderness in the epigastric region, no guarding with sluggish bowel sounds. Infraumbilical laparotomy wound was healthy. Her biochemical profile revealed leukocytosis with neutrophil predominance. Rest of the biochemical investigations were normal. Radiograph of abdomen ( - Fig. $\mathbf{1}$ ) revealed free air under the diaphragm which was expected in post-op setting; however, few loculi of air were also noted just inferior to fundal air. Patient underwent contrast enhanced computerized tomography (CECT) for further evaluation. CECT abdomen
(-Fig. 2) revealed air in walls of the stomach suggestive of pneumatosis consisting of both round as well as few streaky loculi, with subtle wall thickening. No significant air was seen

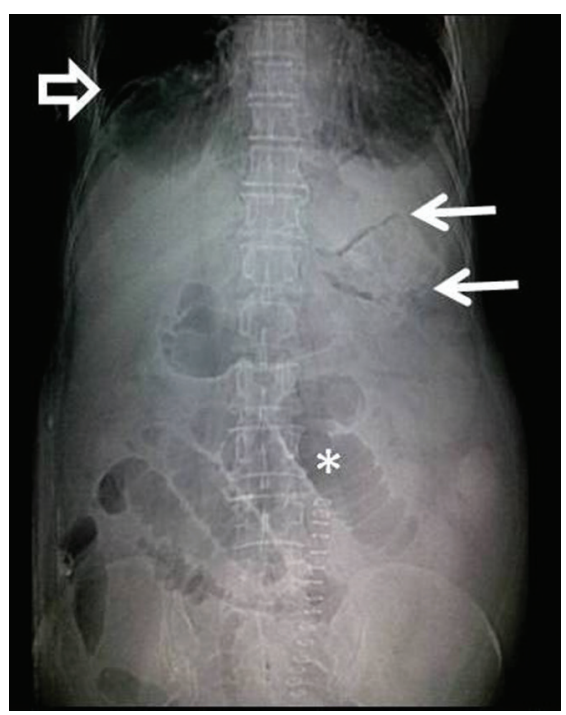

Fig. 1 Supine anteroposterior (AP) radiograph abdomen: free air under the diaphragm (white open arrow), air loculi in the stomach wall suggestive of gastric pneumatosis (white solid arrows), and dilated small bowel loops (white star). received

July 7, 2019

accepted after revision

July 9,2019

published online

October 1, 2019
DOI https://doi.org/

10.1055/s-0039-1696082

ISSN 2581-9933.
(C)2019 Indian Society of

Gastrointestinal and Abdominal

Radiology
License terms

() (1) $\ominus \circledast$ 


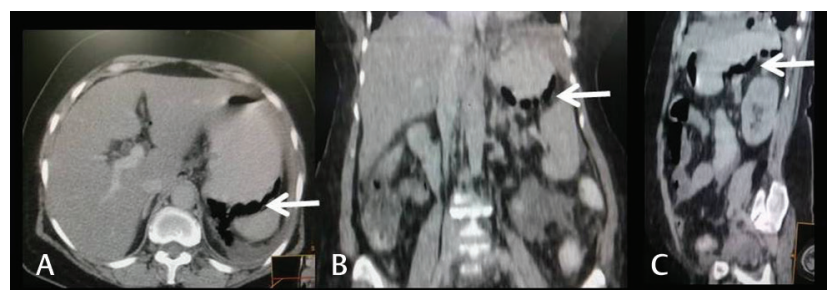

Fig. 2 CECT abdomen: air in the wall of the stomach suggestive of gastric pneumatosis (white solid arrow). (A) axial CECT, (B) coronal MPR, and (C) sagittal MPR. CECT, contrast-enhanced computed tomography; MPR, multiplanar reconstruction.

within the portal vein. No obvious extravasation of oral contrast observed. In given clinical setting, imaging impression of emphysematous gastritis was offered and patient was managed conservatively. Repeat CT scan after 1 week revealed resolution of air in the gastric wall.

\section{Discussion and Review of Literature}

Gastric pneumatosis is a rare finding with less than 100 cases of gastric pneumatosis described in literature in last three decades. ${ }^{2}$ Pneumatosis is uncommon in the stomach due to its acidic contents, abundant blood supply and an efficient mucosal barrier. ${ }^{3,4}$ Gastric pneumatosis signifies presence of an underlying disease with spectrum form of good clinical outcome in GE to high mortality in emphysematous gastritis. ${ }^{1,2}$ Few authors have also described a third condition associated with gastric pneumatosis termed as cystic pneumatosis; however, it appears to be related to gastric emphysema only with same etiologies..$^{5-7}$ Gastric emphysema was first described by Brouardel in 1895 while first case of gastric emphysema was described by Fraenkel in 1889., ${ }^{1,5,7}$

Both conditions have different postulated etiologies with disruption in gastric mucosa is indicated for GE due to dissection of air into the gastric wall while EG is mostly secondary to gas production by bacteria. ${ }^{1,2}$ Various predisposing conditions for GE are raised intragastric pressure mostly secondary to gastric outlet obstruction, instrumentation like postgastroscopy, severe vomiting, or dissection of air from the mediastinum.

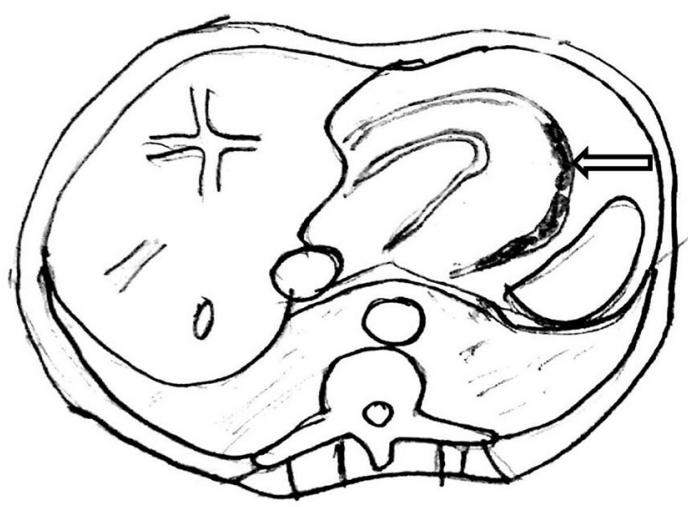

A

Fig. 3 Diagrammatic representation of gastric pneumatosis: axial CECT abdomen images. (A) Gastric emphysema near normal wall thickness with thin round to flat air bubbles in gastric wall (straight open arrow). (B) Emphysematous gastritis Mottled/streaky air in thickened gastric wall (curved open arrow).
For EG, predisposing conditions are alcohol abuse, gastric surgery, recent gastroenteritis, corrosive ingestion, chronic consumption of nonsteroidal anti-inflammatories (NSAIDs)/ steroids, diabetes mellitus, chronic obstructive pulmonary disease (COPD), and immunosuppression. ${ }^{1,2,5}$ The clinical features are nonspecific in both conditions with EG being more severe with high mortality. EG manifests as low-grade fever, chills, nausea, vomiting, severe abdominal pain, hematemesis, or occult gastric bleeding. On examination, the patient is toxic with tachycardia and hypotension suggesting shock like state with severe abdominal tenderness in epigastric region along with reduced bowel sounds. On the other hand, GE has milder symptoms and patient is hemodynamically stable. ${ }^{1,2,5,7}$

Biochemical parameters are generally deranged in EG revealing leukocytosis, elevated lactate, anion gap metaboltigation of choice for diagnosis wherein the radiograph of abdomen may show air in the wall of the stomach. ${ }^{1} \mathrm{CT}$ clearly depicts the presence of air in the stomach wall. Differentiating GE from EG is difficult on basis of CT findings alone; however, in GE the air in the stomach wall usually seen as round air bubbles while in EG air has a streaky and linear consistency with associated gastric wall thickening. Portal venous air may or may not be seen in both GE or EG ( - Fig. 3).,2,5,7,9

Upper gastrointestinal (GI) endoscopy may show a pebble-like gastric mucosa due to presence of air bubbles in the wall. ${ }^{1.5}$ Management in GE is usually conservative while in EG management is still evolving, Watson et $\mathrm{al}^{2}$ in their study on predictors of mortality and management strategies in emphysematous gastritis observed that treatment of choice in EG before year 2000 was exploratory laparotomy with mortality rate of $60 \%$ while after the year 2000 , early endoscopic evaluation and good medical management were treatment of choice leading to reduced mortality rate of approximately 33\%. Thus in EG if clear surgical indications like perforation or bowel necrosis is absent, conservative management with bowel rest by keeping patient nil orally and placing nasogastric tube, providing adequate nutritional support using total parenteral nutrition (TPN), intravenous (IV) fluids, and broad-spectrum antibiotics results in good outcome. . $^{1,2,5,10}$

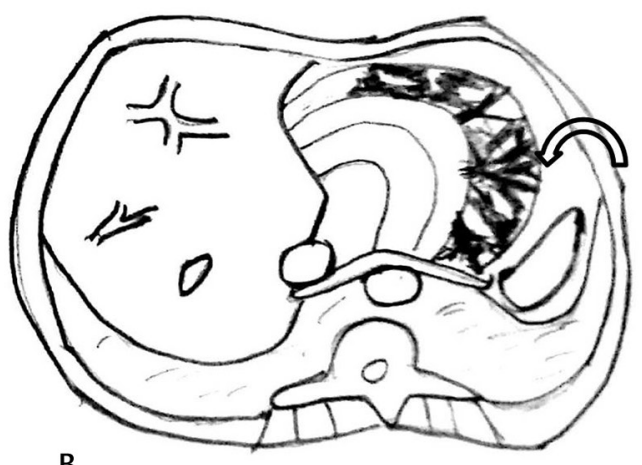

B ic acidosis, and acute kidney injury., ${ }^{5,8}$ Imaging is the inves- 
Table 1 Differences between gastric emphysema and emphysematous gastritis

\begin{tabular}{|c|c|c|c|}
\hline Serial number & Features & Gastric emphysema & Emphysematous gastritis \\
\hline 1 & Etiology & $\begin{array}{l}\text { Disruption in gastric mucosa with dissec- } \\
\text { tion of air into the gastric wall }\end{array}$ & Secondary to gas production by bacteria \\
\hline 2 & $\begin{array}{l}\text { Predisposing } \\
\text { conditions }\end{array}$ & $\begin{array}{l}\text { - Raised intragastric pressure mostly } \\
\text { secondary to gastric outlet obstruction } \\
\text { - Instrumentation like postendoscopy } \\
\text { - Severe vomiting } \\
\text { - Gastric ischemia } \\
\text { - Dissection of air from the mediastinum }\end{array}$ & $\begin{array}{l}\text { - Alcohol abuse } \\
\text { - Gastric surgery } \\
\text { - Recent gastroenteritis, } \\
\text { - Corrosive ingestion } \\
\text { - Chronic consumption of NSAIDs/steroids } \\
\text { - Diabetes mellitus } \\
\text { - COPD } \\
\text { - Immunosuppression }\end{array}$ \\
\hline 3 & $\begin{array}{l}\text { Clinical } \\
\text { features }\end{array}$ & $\begin{array}{l}\text { - Asymptomatic/mild symptoms } \\
\text { - Hemodynamically stable }\end{array}$ & $\begin{array}{l}\text { - Fever } \\
\text { - Nausea/vomiting, } \\
\text { - Severe abdominal pain } \\
\text { - Hematemesis or occult gastric bleeding } \\
\text { - Patient is toxic with tachycardia and } \\
\text { hypotension (hemodynamically unstable) } \\
\text { - Severe abdominal tenderness in epigastric } \\
\text { region } \\
\text { - Reduced bowel sounds }\end{array}$ \\
\hline 4 & $\begin{array}{l}\text { Biochemical } \\
\text { parameters }\end{array}$ & Usually normal & $\begin{array}{l}\text { - Leukocytosis } \\
\text { - Elevated lactate } \\
\text { - Anion gap metabolic acidosis } \\
\text { - Acute kidney injury }\end{array}$ \\
\hline 5 & Imaging & $\begin{array}{l}\text { - Gastric pneumatosis pattern is of } \\
\text { round air bubbles } \\
\text { - Portal vein air may or may not present }\end{array}$ & $\begin{array}{l}\text { - Gastric pneumatosis pattern is of streaky/ } \\
\text { mottled/linear air } \\
\text { - Gastric wall thickening may or may not } \\
\text { present } \\
\text { - Portal vein air may or may not present }\end{array}$ \\
\hline 6 & Treatment & Conservative & $\begin{array}{l}\text { Early endoscopic evaluation and conservative } \\
\text { management if no clear surgical indication }\end{array}$ \\
\hline 7 & Mortality & Low & High \\
\hline
\end{tabular}

Abbreviations: COPD, chronic obstructive pulmonary disease; NSAIDs, nonsteroidal anti-inflammatories.

Differentiating features between GE and EG are summarized in - Table $\mathbf{1}$ with representative images from literature are shown in - Fig. 3. In our case, patient had predisposing conditions for EG like diabetes and abdominal surgery. Clinically, patient had fever, sever epigastric pain, reduced bowel movements with shock like state, and neutrophilic leukocytosis. On imaging, findings of air within the stomach wall with given clinical setting were suggestive of EG. Patient showed clinical improvement with conservative management in form of gut rest and broad-spectrum antibiotics. Also the repeat CT after 1 week revealed resolution of air in the wall of the stomach.

\section{Conclusion}

Gastric pneumatosis is a spectrum ranging from GE to EG. Differentiation between two entities based on clinical presentation, predisposing factors, and radiological findings is important as EG has more complications and higher rates of mortality. The treatment in GE is conservative while treatment in EG is evolving with current emphasis toward conservative management in absences of absolute indications for surgery.

\section{Conflict of Interest}

None declared.

\section{References}

1 López-MedinaG, Castillo Díaz de LeónR, Heredia-SalazarAC, Hernández-SalcedoDR. Gastric emphysema a spectrum of pneumatosis intestinalis: a case report and literature review.Case Rep Gastrointest Med 2014;2014. doi:/10.1155/2014/891360

2 Watson A, Bul V, Staudacher J, Carroll R, Yazici C. The predictors of mortality and secular changes in management strategies in emphysematous gastritis. Clin Res Hepatol Gastroenterol 2017;41(1):e1-e7

3 Hassan S, Abbass K, Markert R, Akram S. Emphysematous gastritis associated with ulcerative esophagitis. Eur Rev Med Pharmacol Sci 2011;15(11):1336-1338

4 Loi TH, See JY, Diddapur RK, Issac JR. Emphysematous gastritis: a case report and a review of literature. Ann Acad Med Singapore 2007;36(1):72-73 
5 Kyawzaw L, Emmanuel O, Sandar L, et al. Case series: gastric emphysema and emphysematous gastritis with air in portal venous system. Gastroenterol Hepatol Open Access 2018;9(1):00289

6 Bilici A, Karadag B, Doventas A, Seker M. Gastric pneumatosis intestinalis associated with malignancy: an unusual case report. World J Gastroenterol 2009;15(6):758-760

7 Misro A, Sheth H. Diagnostic dilemma of gastric intramural air. Ann R Coll Surg Engl 2014;96(7):e11-e13
8 Jehangir A, Rettew A, Shaikh B, Bennett K, Qureshi A, Jehangir Q. A case report of emphysematous gastritis in a diabetic patient: favorable outcome with conservative measures. J Community Hosp Intern Med Perspect 2015;5(4):28010

9 Yao J, Morgan J, Brotman J. Air in the gastric wall of a patient with AIDS. Radiol Case Rep 2017;12(3):491-493

10 Szuchmacher M, Bedford T, Sukharamwala P, Nukala M, Parikh $\mathrm{N}$, Devito P. Is surgical intervention avoidable in cases of emphysematous gastritis? A case presentation and literature review. Int J Surg Case Rep 2013;4(5):456-459 